\title{
PENGARUH FISIOTAPING TERHADAP PENINGKATAN KEMAMPUAN FUNGSIONAL PADA PASIEN OSTEOARTHRITIS
}

\author{
Afrianti Wahyu Widiarti, Sukadarwanto \\ Kementerian Kesehatan Politeknik Kesehatan Surakarta Jurusan Fisioterapi
}

\begin{abstract}
Osteoarthritis, Knee, Fisiotaping, Functional Activity. The aims of the study was to finded the effect of fisiotaping to increased functional activity in patients with osteoarthritis of the knee. a research design that is used is One group pre and post design with control. The research subjects 20 people who suffer from osteoarthritis of the knee who met the study criteria given fisiotaping during 6 weeks of treatment. The research location is Clinic of YPAC Surakarta, Central Java. Measuring Tool used WOMAC Scale. the functional activity (WOMAC) normality test of data, data are normally distributed then tested with paired sample $t$ test. The results of the functional significance of the activity before and after the treatment has a value of $p=0.000(p<0.05)$, which means there fisiotaping effect of increased functional activity.
\end{abstract}

Key Words: Osteoarthritis, Knee, Functional Activity, Fisiotaping

\begin{abstract}
Abstrak: Osteoartritis, Lutut, Fisiotaping,Aktivitas Fungsional. Tujuan penelitian ini adalah mengetahui pengaruh Fisiotaping terhadap peningkatan kemampuan fungsional penderita osteoartritis lutut. Desain Penelitian One group pre and post design with control. subyek penelitian sejumlah 20 orang yang menderita osteoartritis lutut yang memenuhi kriteria penelitian diberikan pemasangan fisiotaping selama 6 minggu. Tempat penelitian Klinik YPAC Surakarta, Jawa Tengah. Alat Ukur yang digunakan WOMAC Scale. Uji normalitas data aktivitas fungsional (WOMAC), data berdistribusi normal menggunakan parametrik paired sample $t$ test. Hasil signifikansi aktivitas fungsional sebelum dan setelah perlakuan memiliki nilai $\mathrm{p}=0,000(\mathrm{p}<0,05)$, yang berarti ada pengaruh fisiotaping terhadap peningkatan aktivitas fungsional.
\end{abstract}

Kata Kunci: Osteoartritis, Lutut, Fisiotaping,Aktivitas Fungsional

\section{PENDAHULUAN}

Usia harapan hidup meningkat dari 54 tahun pada wanita dan 50 tahun pada laki - laki ( pada tahun 1980 ) menjadi 61,5 tahun untuk wanita dan 57,5 tahun untuk laki -laki pada tahun 1985. Pada tahun 1990 mencapai 64,7 tahun untuk wanita dan 61 tahun untuk laki - laki, sedangkan pada tahun 1995 usia harapan hidup telah mencapai 66,7 tahun untuk wanita dan 62,9 tahun untuk laki - laki ( Depkes RI, 2003)
Osteoartritis adalah penyakit degeneratif pada sendi yang ditandai gejala patologis pada seluruh struktur sendi. Adanya kerusakan tulang rawan sendi, munculnya skelerosis dan osteofit pada tepi tulang, meregangnya kapsul sendi, timbul peradangan dan lemahnya otot-otot disekitar sendi (Felson, 2008).

Osteoartritis banyak disebabkan oleh berbagai faktor antara lain usia, obesitas, jenis kelamin dan aktivitas 
fisik serta idiopatik. Seiring bertambahnya usia, tingkat penggunaan sendi lebih tinggi tetapi kemampuan sel untuk regenerasi menurun dan kemampuan otot berkurang. Meningkatnya berat tubuh hingga obesitas akan mempengaruhi kerja sendi lutut untuk menopang tubuh. Sehingga beban sendi lutut untuk menopang tubuh akan meningkat. Selain itu aktivitas fisik yang berlebih menimbulkan beban yang cukup berat pada sendi lutut dan beresiko cidera hingga resiko terkena osteoartritis, tetapi banyak kasus tidak dapat ditemukan penyebab dengan jelas (Apley, 1995).

Berbagai upaya telah dilakukan oleh fisioterapis dalam mengatasi nyeri dan fungsional dengan berbagai modalitas fisioterapi, modalitas fisioterapi yang aman dan praktis bisa dijadikan sebagai alternatif yang tepat dan cepat dalam mengatasi masalah nyeri, modalitas yang kurang begitu dikenal namun telah banyak yang membuktikan keefektifannya dalam mengatasi masalah muskuloskeletal, modalitas tersebut adalah taping.

Sementara itu, fisiotaping hadir sebagai modalitas fisioterapi yang aman dan praktis, bisa dijadikan sebagai alternatif yang tepat dan cepat dalam mengatasi nyeri dan perbaikan fungsional. Fisiotaping adalah upaya intervensi fisioterapi dengan menggunakan metode pembalutan elastis yang direkatkan pada kulit serta di desain sedemikian rupa sehingga mempunyai efek terapeutik atau pengobatan (Kuntono, 2011).

Dasar dari fisiotaping adalah penemuan elastis taping yang dikembangkan oleh Kenzo Kase (1973) dengan istilah Kinesiotaping. Efek dari rekatan dikulit memberikan efek stimulus mikrosensoris terhadap permukaan kulit sehingga merasa lebih nyaman. Sedangkan Efek dari sistem sirkulasi lympatik dan sirkulasi darah, akan memberikan perbaikan vaskularisasi sehingga mengurangi udema. Efek terhadap otot dan tendon akan memberikan fasilitasi dan inhibisi kontraksi sehingga kerja otot tetap optimal dan nyeri dapat dimodulasi (Kuntono, 2011). Sifat- sifat elastis juga dapat digunakan secara mekanis untuk membatasi atau mendorong gerakan tertentu di sendi (Kaze, 2005).

Modalitas ini memang kurang dikenal oleh fisioterapis khususnya di Indonesia, padahal taping merupakan tindakan fisioterapi yang mudah dan memberikan efek baik. Dengan taping dapat mengurangi nyeri secara cepat, dengan beberapa aplikasi pendekatan yang dapat digunakan untuk meningkatkan kekuatan otot, koreksi pada sendi, fascia, dan jaringan lain yang berkaitan dengan fungsi musculoskeletal. Fungsi utama dari kinesiotaping ini adalah untuk memberikan elastis lebih kuat bagi otot otot yang terasa tegang dan juga melindungi atau mendukung otot. Beberapa orang juga mengunakan kinesiotaping ini untuk mencegah kemungkinan terjadinya odema karena kelelahan dan kejang otot. Pemakain taping dapat meningkatkan kekuatan dan energi yang hilang bersamaan sewaktu melakukan pergerakan (Stewart Bruce, 2008).

\section{METODE PENELITIAN}

Desain penelitian ini adalah "One group Pre \& post test Design with control" dimana subyek dibagi menjadi 2 kelompok. Kelompok 1 diberikan perlakuan berupa Fisioterapi standar dan setelahnya diberikan Fisiotaping, sedangkan pada kelompok kontrol 
hanya diberikan Fisioterapi standar. semua pasien yang berkunjung di klinik YPAC yang memenuhi kriteria dan bersedia menjadi subyek penelitian.

Seluruh subyek penelitian telah memenuhi kriteria penerimaan yang telah ditentukan, meliputi : (1) penderita Osteoartritis baik laki-laki maupun perempuan, ditegakkan oleh diagnosa dokter, (2) memenuhi kriteria hasil pemeriksaan yang menunjukan adanya nyeri akibat osteoartritis yaitu nyeri di lutut kanan atau kiri saat beraktifitas dan saat pagi hari dan mempunyai nilai VAS quadriple (nyeri rata-rata dlm 24 jam terakhir) antara $2-7$ (3) bersedia mengikuti program terapi satu minggu 2 kali berturut-turut selama 6 minggu, 4) penderita osteoartritis grade 1 sampai 3 .

Teknik pengumpulan data dalam penelitian ini adalah dengan pengukuran kemampuan fungsional menggunakan kuesioner Womac Scale. Data yang telah diperoleh selanjutnya dianalisis. Sebelumnya dilakukan uji normalitas data menggunakan Shapiro wilk test karena data $<50$. Setelah diperoleh data berdistribusi normal, analisis statistik yang digunakan adalah paired sample ttest.

\section{HASIL PENELITIAN}

\section{Analisis Univariat}

Karakteristik subyek penelitian

Subyek penelitian ini adalah 20 (dua puluh) orang.

\section{Tabel 1}

Deskripsi Subjek Penelitian Berdasarkan Usia

\begin{tabular}{|c|c|c|c|c|}
\hline & \multicolumn{2}{|c|}{ Kelompok I } & \multicolumn{2}{|c|}{ Kelompok II } \\
\hline & $\begin{array}{r}\mathrm{Te} \\
\mathrm{Sta} \\
+ \text { Fisi } \\
\end{array}$ & $\begin{array}{l}\mathrm{i} \\
\mathrm{r} \\
\operatorname{sing}\end{array}$ & Terapi & andar \\
\hline Usia & Jumlah & $\%$ & Jumlah & $\%$ \\
\hline $32-36$ & - & - & 2 & 20 \\
\hline $37-42$ & - & - & 4 & 40 \\
\hline $43-47$ & 4 & 4 & - & \\
\hline
\end{tabular}

\begin{tabular}{lllll} 
& & 0 & & \\
$48-52$ & 6 & 6 & 4 & 40 \\
& & 0 & & \\
\hline Total & 10 & 1 & 1 & 100 \\
& & 0 & 0 & \\
& & 0 & & \\
\hline
\end{tabular}

Mean usia pada kelompok I didominasi oleh penderita dengan rentang usia 43-47 tahun berjumlah 4 orang $(40 \%)$, dan dengan penderita berusia 48-52 berjumlah 6 orang (60\%). Sedangkan pada kelompok II antara 32-36 adalah 2 orang (20\%), usia $37-42$ ada 4 orang (40\%) dan usia 48-52 ada 4 orang (40\%). Rerata umur pada kelompok I didapatkan 48, sedangkan pada kelompok II didapatkan nilai rerata 41,6 .

\section{Tabel 2}

Deskripsi Subjek Penelitian

Berdasarkan Jenis Kelamin Kelompok I Kelompok II

Terapi Terapi

Standar $+\quad$ Standar

Fisiotaping

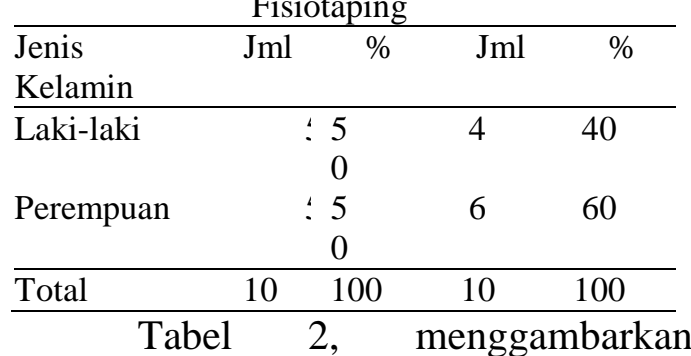

karakteristik jenis kelamin subjek penelitian. Kelompok perlakuan I adalah 5 orang laki-laki $(50 \%)$ dan 5 orang perempuan (50\%). Pada kelompok perlakuan II adalah 4 orang laki-laki $(40 \%)$ dan 6 orang perempuan $(60 \%)$. Sehingga jumlah total subyek penelitian jenis kelamin laki-laki adalah 9 orang (45\%) dan perempuan adalah 11 orang $(55 \%)$.

Pada awal penelitian ini subyek diukur dan kemampuan fungsional dengan WOMAC SCALE. Deskripsi dari nilai WOMAC Scale sebelum 
perlakuan pada kelompok I diperoleh nilai minimal 57 maksimal 86 rata-rata 72,5 sedangkan untuk kelompok II diperoleh nilai minimal 55 maksimal 86 rata-rata 72,33. Hasil pengukuran awal subyek penelitian ini dapat dilihat pada tabel 3 sebagai berikut:

\section{Tabel 3}

Nilai WOMAC Scale Sebelum

Perlakuan

Kelompok Minimal Maksimal Rata-rata

\begin{tabular}{lllc}
\hline I & 57 & 86 & 72,5 \\
II & 55 & 87 & 72,3 \\
\hline
\end{tabular}

Setelah dilakukan perlakuan selama 6 minggu, nilai WOMAC scale setelah perlakuan pada kelompok I diperoleh nilai minimal 23 maksimal 35 rata-rata 30,9 sedangkan untuk kelompok II diperoleh nilai minimal 45 maksimal 80 rata-rata 64,6 untuk lebih jelasnya dapat dilihat pada tabel 5.4

\section{Tabel 4}

\section{Nilai WOMAC Scale Setelah}

\section{Perlakuan}

Kelompok Minimal Maksimal Rata-rata

\begin{tabular}{cccc}
\hline I & 23 & 35 & 30,9 \\
\hline II & 45 & 80 & 64,6 \\
\hline
\end{tabular}

Variabel kemampuan fungsional

kelompok I terdapat perbedaan nilai rata-rata sebelum perlakuan 72,5, sesudah perlakuan 30,9 atau terjadi perubahan 41,6, sedangkan kelompok II terdapat perbedaan nilai rata-rata sebelum perlakuan 72,3 , sesudah 64,6 atau ada perubahan 7,7.

Uji beda statistic aktivitas fungsional dimana data berdistribusi normal, diperoleh nilai Womac Osteoarthritis Index sebelum dan setelah perlakuan yaitu $\mathrm{p}=0,000$ yang secara bermakna ada pengaruh pemakaian fisiotaping terhadap peningkatan aktivitas fungsional pada penderita OA lutut.

\section{PEMBAHASAN}

Hasil pada penelitian ini sejalan dengan penelitian yang dilakukan oleh Cushnaghan et.al (1994) berjudul Taping the patella medially: a new treatment for osteoarthritis of the knee joint, dengan 14 subyek penelitian yang secara acak mendapatkan 3 perlakuan yang sama dengan teknik pemasangan taping yang berbeda (medial, lateral dan netral). Didapatkan hasil $\mathrm{p}=0,023$ ( $p<0,05)$, hal ini menunjukkan bahwa pemberian taping berpengaruh terhadap penurunan nyeri pada penderita OA lutut. Selain itu juga penelitian yang dilakukan oleh Brandon et.al (2005) dengan judul The use of Kinesio Tape in patients diagnosed with Patellofemoral pain, diperoleh hasil Kinesio Tape berpengaruh dalam memberikan efek yang positif untuk mengurangi nyeri pada penderita patellofemoral pain.

Bukti lain juga ditunjukkan dalam penelitian yang dilakukan oleh Crossley et.al (2009) dengan judul Can patellar tape reduce the patellar malalignment and pain associated with patellofemoral osteoarthritis?, dengan 28 subyek penelitian yang dibagi menjadi 2, yaitu kelompok perlakuan dengan taping dan kelompok kontrol tanpa taping. Diperoleh hasil, subyek penelitian dengan OA sendi lutut yang menggunakan patellar taping secara signifikan dapat mengurangi malalignment $(\mathrm{p}=0,028)$ dan rasa nyeri $(p=0,045)$. DJ.Osterheus (2004) juga membuktikan dalam penelitian The use of Kinesio Taping in the management of traumatic patella dislocation. A case study. Physiotherapy Theory and Practice, dengan 1 subyek penelitian seorang wanita berusia 49 tahun, setelah 5 minggu pemasangan taping didapatkan hasil terdapat 
penurunan nyeri dan oedema dan pola jalan yang normal. Penelitian The effects of Kinesiotape and strength training on knee pain and quadriceps strength in people with patellofemoral pain syndrome (PFPS)yang dilakukan oleh Mousavi et.al (2011) dengan 31 pasien pria yang menderita PFPS, diperoleh hasil secara signifikan Kinesio Tape berpengaruh terhadap penurunan nyeri pada pasien PFPS.

Mekanisme kerja dari fisiotaping adalah dengan cara merangsang proprioceptor yang merespon nyeri, merangsang mechanoreceptors, memfasilitasi drainase limfatik dengan mengangkat kulit untuk menciptakan area bertekanan rendah (Kase, 2005).

Fisiotaping yang dilekatkan pada sendi lutut akan mengangkat kulit sehingga terjadi proses eliminasi tekanan kutan terhadap jaringan subcutan yang menghasilkan area bertekanan rendah. Hal ini akan mengakibatkan pembuluh darah dan limfe menjadi vasodilatasi sehingga jaringan yang mengalami hipoksia dan asidosis dapat teraliri darah yang mengandung nutrisi dan oksigen. Dengan adanya vasodilatasi pembuluh darah tersebut akan memperlancar sistem metabolisme pada area yang diterapi sehingga substansi nyeri seperti bradikinin, prostaglandin dan histamine akan terbuang bersama dengan aliran darah sehingga nyeri akan menurun. Di sisi lain, dengan adanya metabolisme yang lancar, akan terjadi pembuangan sisa metabolisme penumpukan asam laktat yang menyebabkan spasme. Keuntungan metabolisme ini mengakibatkan spasme otot menjadi menurun (Kase, 2005).

Selain proses menurunkan nyeri melalui area bertekanan rendah, fisiotaping juga dapat menurunkan nyeri melalui teori gerbang kontrol. Adanya sentuhan berupa gosokan pada saat pemasangan fisiotaping akan menstimulasi mekanoreseptor yang dapat merangsang serabut A-beta yang merupakan serabut berdiameter besar dan lebih cepat dalam melepaskan neurotransmitter penghambat. Selain itu, serabut A-beta adalah penghantar rangsang non- nociceptive (bukan nyeri). Berbeda dengan serabut A-delta dan $C$ yang berdiameter kecil yang merupakan serabut pembawa rangsang nosiseptif. Selanjutnya serabut A-beta akan mengaktivasi substansia gelatinosa (SG) untuk menutup gerbang ke pusat (otak) sehingga rangsang nyeri yang menuju pusat akan terhenti atau menurun (Kuntono, 2011).

\section{KESIMPULAN DAN SARAN}

Berdasarkan penelitian yang dilakukan pada 10 orang penderita osteoartritis sendi lutut yang diberikan fisiotaping selama 6 minggu, dimana aktivitas fungsionalnya dievaluasi dengan WOMAC Scale, diperoleh kesimpulan sebagai berikut.

Pemberian fisiotaping pada penelitian ini memiliki pengaruh terhadap peningkatan aktivitas fungsional pada penderita osteoartritis sendi lutut yang diukur dengan WOMAC Scale. Hal ini juga dapat diketahui dari hasil analisis statistik dengan menggunakan paired sample t test. Diperoleh nilai $\mathrm{p}=0,000$ yang artinya secara bermakna ada pengaruh yang diberikan fisiotaping terhadap peningkatan aktivitas fungsional.

Dari hasil analisis yang didapatkan, fisiotaping memiliki manfaat untuk mengurangi nyeri sehingga dapat meningkatkan aktivitas fungsional pada penderita osteoartritis sendi lutut. 
Saran dari penelitian ini adalah (1) fisiotaping dapat digunakan sebagai modalitas tambahan pada penderita osteoartritis sendi lutut untuk mengurangi nyeri dan meningkatkan aktivitas fungsional, (2) diperlukan penelitian yang lebih lanjut dengan subyek yang lebih banyak, waktu yang lebih panjang dan adanya follow up setelah diberikan perlakuan untuk melihat manfaat fisiotaping dalam jangka waktu panjang.

\section{DAFTAR RUJUKAN}

Apley, A.Graham.1995. Buku Ajar Orthopedi dan Fraktur Sistem Apley: Edisi ketujuh. Jakarta; Widya Medika.

Crossley K.M, et.al. 2009. Can Patellar Tape Reduce the Patellar Malalignment and Pain Associated with Patellofemoral Osteoarthritis?; Diakses pada tanggal 9 Mei 2012, dari http://www.ncbi.nlm.nih.gov/pu bmed/19950307

Cushnaghan, et.al. 1994. Taping the Patella Medially: a New Treatment for Osteoarthritis of the Knee Joint?; Diakses tanggal 9 Mei 2012, dari http://www.bmj.com/

Depkes RI. 2003. Pedoman Pengelolaan Kegiatan Kesehatan di Kelompok Lanjut Usia. Depkes :Jakarta

Kaze, D.C. 2005. Illustrated Kinesio Taping : Edisi Ke 4, Ken'i-kai, Tokyo, Hal 6-15.

Kuntono, H.P. 2011. Fisiotaping Metode Terkini Untuk Problem Nyeri, disampaikan dalam seminar nasional fisioterapi; Surakarta, 12 Maret 2011.

Kuntono, H.P.2011. Nyeri secara
Umum dan Osteo Arthritis Lutut dari aspek Fisioterapi; Muhammadiyah University Press, Surakarta.

Mousavi, S.M, et.al, 2011; The Effects of Kinesiotape and Strength Training on Knee Pain and Quadriceps Strength in People with Patellofemoral Pain Syndrome (PFPS); Diakses tanggal 9 Mei 2012, dari http://www.jims.mui.ac.ir/ 